\title{
The earthquake lights (EQL) of the 6 April 2009 Aquila earthquake, in Central Italy
}

\author{
C. Fidani \\ Dipartimento di Fisica, Universitá di Perugia, Via A. Pascoli, Perugia, Italy
}

Received: 30 December 2009 - Revised: 22 March 2010 - Accepted: 12 April 2010 - Published: 7 May 2010

\begin{abstract}
A seven-month collection of testimonials about the 6 April 2009 earthquake in Aquila, Abruzzo region, Italy, was compiled into a catalogue of non-seismic phenomena. Luminous phenomena were often reported starting about nine months before the strong shock and continued until about five months after the shock. A summary and list of the characteristics of these sightings was made according to 20th century classifications and a comparison was made with the Galli outcomes. These sightings were distributed over a large area around the city of Aquila, with a major extension to the north, up to $50 \mathrm{~km}$. Various earthquake lights were correlated with several landscape characteristics and the source and dynamic of the earthquake. Some preliminary considerations on the location of the sightings suggest a correlation between electrical discharges and asperities, while flames were mostly seen along the Aterno Valley.
\end{abstract}

\section{Introduction}

This study presents the preliminary results of a collection of testimonies about luminous phenomena related to seismic activity in and near Aquila before and after the main seismic event $(M=6.3)$, at 03:32 LT on 6 April 2009. The main shock caused strong shaking in and near Aquila causing heavy damage and 307 casualties. The earthquake of 6 April 2009 was the strongest event in a sequence of seismic events that started a few months earlier; local seismic activity began to increase in December 2008 (Pondrelli, 2010). The most significant prior events occurred on 30 March $(M=4.4)$, at 15:38 LT, 5 April $(M=4.2)$, at 22:48 LT and 6 April $(M=3.9)$, at 00:39 LT (Chiarabba, 2009). The main shock was followed by seven aftershocks within the first week; the moment mag-

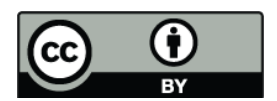

Correspondence to: C. Fidani (cristiano.fidani@ fisica.unipg.it) nitude $\left(M_{w}\right) \geq 5$, the two strongest ones occurred on 7 April $(M=5.6)$, at 19:47 LT, and on 9 April $(M=5.4)$, at 02:52 LT, (Bindi, 2009). A summary of the Aquila seismic sequence is reported; earthquake times are compared with times of EQL (Table 1).

A complete account of previous testimonials already compiled (Fidani, 2005), dating back as far as $2000 \mathrm{BC}$ and continuing to the present day, regard only vague statements concerning the general features of luminosity. A critical review of luminous testimonies has stressed the importance of selecting a scientific scope (Stothers, 2004). Middle-Age legends have also been reinterpreted in a multidisciplinary manner taking into account luminous phenomena (Piccardi, 2005). The first collection of EQL data was compiled in Italy in the early 20 th century by the religious naturalist Ignazio Galli; it contained a first ordering of historical phenomena based on the shapes and time evolutions (Galli, 1910). Seismological studies have also taken into account historical luminous phenomena, recognizing them as just the darkest chapter in seismology (Sieberg, 1911). The same phenomena have been recorded in Japan (Terada, 1931), along with tsunamis (Terada, 1934). Frederic Montandon proposed a revised classification which reduced Galli's number of EQL types from nine to five (Montandon, 1948). The first EQLs were photographically documented in 1966 along with a report containing numerous testimonials during an earthquake swarm near Matsushiro (Yasui, 1973). A review of observations has highlighted the well established existence of luminous phenomena plus proposed theories (Derr, 1973). After Galli's collection, EQLs were reported in Italy on two rare occasions: the Irpinia earthquake in 1930 (Oddone, 1930; Alfano, 1931) and the Friuli earthquake in 1976 (Matteucig, 1985). Further reports have been published on cities in Canada (St-Laurent, 2000), Mexico (Araiza-Quijano, 1996), Japan (Enomoto, 1998), Greece (Soter, 1999) and more recently in Peru (Lira, 2008). 
Table 1. The earthquake sequence list, time in LT and depth in $\mathrm{km}$.

\begin{tabular}{lccccc}
\hline Date & Time & $M_{\mathrm{W}}$ & Latitude & Longitude & Depth \\
\hline 30 Mar 2009 & $15: 38$ & 4.4 & 42.321 & 13.376 & 9.8 \\
30 Mar 2009 & $23: 57$ & 3.6 & 42.316 & 13.375 & 9.5 \\
2 Apr 2009 & $13: 11$ & 2.9 & 42.310 & 13.374 & 10.1 \\
3 Apr 2009 & $06: 44$ & 3.3 & 42.314 & 13.376 & 9.2 \\
5 Apr 2009 & $22: 48$ & 4.2 & 42.325 & 13.382 & 9.5 \\
6 Apr 2009 & $00: 39$ & 3.8 & 42.329 & 13.385 & 10.0 \\
6 Apr 2009 & $03: 32$ & 6.3 & 42.343 & 13.380 & 8.9 \\
6 Apr 2009 & $04: 37$ & 5.1 & 42.360 & 13.328 & 8.7 \\
6 Apr 2009 & $05: 56$ & 4.5 & 42.335 & 13.386 & 9.3 \\
6 Apr 2009 & $18: 38$ & 4.4 & 42.363 & 13.339 & 10.0 \\
7 Apr 2009 & $01: 15$ & 5.1 & 42.363 & 13.385 & 9.7 \\
7 Apr 2009 & $19: 47$ & 5.6 & 42.303 & 13.486 & 13.3 \\
9 Apr 2009 & $02: 52$ & 5.4 & 42.484 & 13.343 & 15.4 \\
9 Apr 2009 & $21: 38$ & 5.2 & 42.501 & 13.356 & 17.2 \\
12 Apr 2009 & $20: 05$ & 3.6 & 42.384 & 13.388 & 9.8 \\
13 Apr 2009 & $23: 14$ & 5.0 & 42.498 & 13.377 & 9.0 \\
26 Apr 2009 & $19: 56$ & 3.5 & 42.456 & 13.378 & 10.6 \\
5 May 2009 & $20: 03$ & 3.3 & 42.270 & 13.509 & 10.1 \\
10 May 2009 & $18: 00$ & 3.8 & 42.301 & 13.479 & 10.0 \\
7 Jun 2009 & $21: 22$ & 3.9 & 42.350 & 13.483 & 10.4 \\
11 Jun 2009 & $19: 21$ & 3.7 & 42.335 & 13.438 & 10.6 \\
15 Jun 2009 & $17: 21$ & 3.4 & 42.439 & 13.445 & 10.1 \\
29 Jun 2009 & $07: 54$ & 3.4 & 42.463 & 13.366 & 13.5 \\
03 Jul 2009 & $13: 03$ & 4.3 & 42.409 & 13.387 & 8.8 \\
31 Aug 2009 & $16: 09$ & 3.3 & 42.250 & 13.517 & 10.0 \\
24 Sep 2009 & $18: 14$ & 4.4 & 42.453 & 13.330 & 9.7 \\
30 Sep 2009 & $14: 02$ & 2.6 & 42.297 & 13.527 & 18.8 \\
\hline
\end{tabular}

The processes to explain luminous phenomena were thought to be due to charge recombination. Thus, a separation of charge was necessary and was explained by some physical effect such as: streaming potential (Terada, 1931), piezoelectric (Finkelstein, 1973), water pore vaporization and droplet disruption (Lockner, 1983) and localized charge remains (Lockner, 1985). Sonoluminescence was also proposed as a possible process associated with seismic waves (Johnston, 1991). A recently study on positive charge generation in igneous rocks opened the way to explaining luminous and other phenomena in a single coherent physical model (Freund, 2002). Charge accumulations at asperities in the crust can produce corona discharges accompanied by the emission of light (St-Laurent, 2006). Laboratory experiments on electrification obtained from mechanical damage were also performed (Schloessin, 1985). Light emission from failing granite was tested (Brady, 1986). Experimental data on electrical currents streaming out of stressed igneous rocks also produced positive results (Freund, 2009).

The method and aim of performing the collection will be given in the next section. Section 3 concerns the collected testimonials and documents. Section 4 presents some interesting observations that emerged from the first order- ing through old classifications and newer classifications for space-time order, which allow for some interesting interpretations that are discussed in Sect. 5.

\section{The collection of testimonials and their scopes}

The collection of testimonials began a few days after the main shock on 11 April 2009 in the Amatrice area (Lazio region) of Italy, about $50 \mathrm{~km}$ north of Aquila. A systematic regional survey of the population was carried out using questionnaires (Soter, 1999). The testimonies were collected by visiting the 179 camps prepared by the Italian Civil Protection (PotezioneCivile, 2009). Testimonials were also collected in meeting places such as schools, malls, hospitals, coffee shops and social clubs. Furthermore, to collect data and supporting documents, personnel at public and private institutions such as the police, firemen, as well as forest rangers were interviewed. The order of the interviews moved from the least hit areas in the Rieti province to the most hit areas in Aquila.

The aims of this data collection were to: 1) instruct the general public on the existence of these earthquake-associated phenomena; 2) propose new hypotheses on earthquake processes; and 3) suggest new devices for systematic recording of these phenomena. At the time of the interviews less than $1 \%$ of the people interviewed knew something about such phenomena; even though in the past Italy was one of the principal EQL research study centers (Fidani, 2005), with many 18 th century reports that frequently described all the phenomena (Galli, 1910). On the other hand, atmospheric, electromagnetic and physiologic phenomena, which were observed mainly before and after the shaking, needs to be included in a larger process to be explained. Thus, new instrument-based hypotheses are expected to give a notable contribution, and can now be tested by low cost digital technology.

The main part of the data collection regards luminous phenomena which were abundantly observed on this occasion. Secondary phenomena concern fluid emissions, chasms, thermal release, unusual meteorological phenomena and sounds, radio and telecommunication disturbances and either human physiological alterations or changes in animal behavior. A questionnaire was compiled to collect valuable information on the public perception (Bird, 2009) of these phenomena, for which no instruments were active at the time and site of the Aquila earthquake. The questions were inspired from previous works (Galli, 1910; Terada, 1931; Matteucig, 1985; Persinger, 1990; Soter, 1999; St-Laurent, 2000; Stothers, 2004) and are listed in the supplementary material (http://www.nat-hazards-earth-syst-sci.net/10/967/2010/ nhess-10-967-2010-supplement.pdf)

The questionnaire began with questions of general nature and led up to more specific ones; related questions were grouped which allowed for a smooth transition from one group to the next (Sarantakos, 2005). The question response 
format included a combination of both open questions, to describe the observations and closed questions to obtain associated facts, as well as to test the coherency of response of each overall testimony. The type of question included classification, knowledge and perception. Classification was limited to place of residence and name of witness, so the witnesses could be contacted for further questions (Bird, 2009). The diffusion of photo and video recordings has greatly contributed to successfully and systematically studying EQL phenomena. Hence, photos and video recordings of sightings were requested and collected during the interviews.

The questionnaire was administered in a face-to-face mode of delivery, which reduced witness conditioning and allowed as much information as possible to be collected. Telephone and e-mail interviews were done, when witnesses could not be reached physically (Bird, 2009). The interview area in the epicenter zone was not complete; but was principally reached in the civil protection camps where people were gathered for meals. The manner of interviewing was carried out on an individual basis and in groups of up to twenty people. When a testimonial was collected but made by a third party, a search was performed to track down the original witness. Then, when possible, during the next trip to the zone, the original witness was interviewed, or contacted by phone or e-mail. Non-probability techniques were used to select the sample: accidental, purposive or snowball (Bird, 2009). These were principally used because of the social difficulties and the emergency housing situation. Therefore, statistical generalisations could not be made. However, this was not one of the aims of this work.

About one thousand two hundred interviews were carried out, in which many witnesses did not see anything while many others reported multiple sightings and of these 1057 cases of macroscopic anomalies were reported which had occurred before, during and after the earthquake. A summary of the testimonial types collected is given in Table 2 .

\section{EQL witnesses}

Many people reported seeing peculiar sightings of light glows, flashes, lightning, flames and fireballs, all of which were considered candidates for EQL. Three eyewitness reported observing high flames which were later identified as explosions of gas cylinders. Tens of sightings were reported as being particularly luminous points in the sky which, through their collected positions, revealed utilising astronomical software to be the planet Venus. The meteorological situation was also taken into consideration for Aquila (http://www.caputfrigoris.it/) so as to discard luminous events of a meteorological nature. Some of such events were observed above the mountains around Aquila and may have originated behind them. For this motif, time and direction of such lightning and the meteorological conditions in Central Italy were also compared (http://www.ilmeteo.it/). Several atmospheric lights were associated with thunder-
Table 2. The different kinds of phenomena collected after 6 April 2009 , near and far from the city of Aquila. Near means $<20 \mathrm{~km}$ from the epicenter, far means $>20 \mathrm{~km}$ from the epicenter.

\begin{tabular}{lrrr}
\hline Kinds & $\begin{array}{c}\text { Near } \\
(\#)\end{array}$ & $\begin{array}{c}\text { Far } \\
(\#)\end{array}$ & $\begin{array}{c}\text { Tot } \\
(\#)\end{array}$ \\
\hline Earthquake lights & 230 & 11 & 241 \\
Radio-telecommunications & 68 & 16 & 84 \\
Unusual sounds & 55 & 14 & 69 \\
Unusual fluid emissions & 144 & 18 & 162 \\
Soil deformations & 25 & 5 & 30 \\
Unusual meteorology & 140 & 26 & 166 \\
Biological anomalies & 256 & 49 & 305 \\
\hline
\end{tabular}

storms. Roughly one hundred sightings were linked with natural phenomena such as sunsets, moon halos and fog illuminations. For example, many witnesses reported seeing a strange moon light which appeared red and was surrounded by a small red halo. This phenomenon was observed at nearly all the locations, from Amatrice to San Pio delle Camere. In this study this phenomenon was considered to be atmospheric. Additionally, eyewitnesses reported observing the breakdown of electrical lines. Many flashes were also compatible with relatively small discharges coming from the ground during the main shock. Being so, the flashes could have been short circuits, given that the area in and around Aquila is highly urbanised. All of these sightings which were identified as being of a natural or anthropogenic source, were excluded from the collection of luminous phenomena. Further verifications concerned a comparison with meteor showers which were discarded for their notable differences with these sightings and absence of abundant phenomena during the considered period. Meteoroid events, revealed by the Italian network of observers (http://www. ciph-soso.net/SOSO/HomePage.html), were not in agreement with any testimonials. The 241 sightings which remained are grouped according to Galli's classification and, because of the high number, only representative samples of testimonials are reported for each group. The complete list of testimonials can be found in the supplementary material (http://www.nat-hazards-earth-syst-sci.net/10/967/2010/ nhess-10-967-2010-supplement.pdf) and several other descriptions can be found elsewhere (Fidani, 2009a,b, 2010).

Diffused light was reported in 38 testimonials principally appearing as reddish light, with shades ranging from orange to violet. The sightings occurred in the historical center of Aquila, its immediate surrounding areas of Pile, San Sisto, Roio and Pettino, as well as the surrounding villages of Cansatessa, Preturo, Cesi, Scoppito, Madonna della Strada, Sassa, Tornimparte, Coppito, Bagno, Pianola, Monticchio and Poggio Picenze, plus the towns of Paganica and Amatrice. Nearly all of these testimonials described diffused halos which were uniform in the sky having a dull rose 


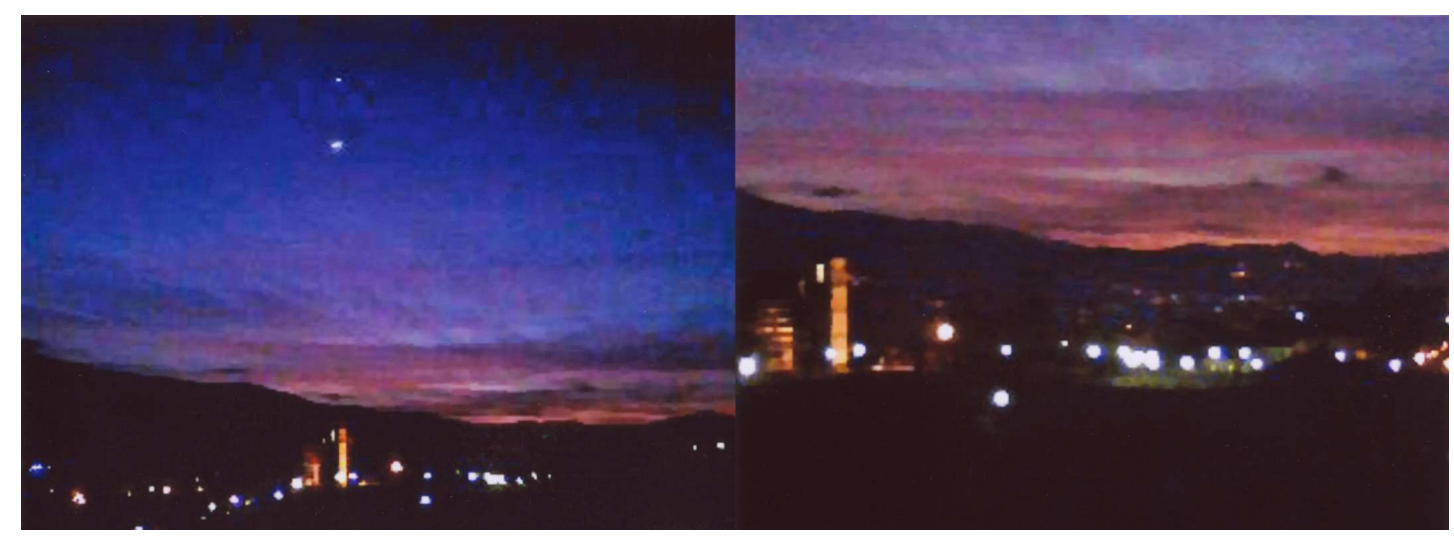

Fig. 1. Reddish diffused light photos from Poggio Picenze towards Aquila (WNW) at about 22:30 LT on 5 April 2009. Courtesy of Lucia Miconi.

coloured luminosity. All testimonials described the colour as being brighter over the mountain crests. Some photos were taken from the village of Poggio Picenze at about 22:30 LT on 5 April in the direction of Aquila just before the 22:48, $M=4.2$ foreshock. In the left photo of Fig. 1, the Moon and Saturn appear in positions that confirm this date and time. These photos are grainy as they were taken with a SAMSUNG SGH i320 mobile telephone camera. Giorgia Zenadocchio affirmed that after the main shock the sky was still reddish from Pettino toward the Velino-Sirente mountain range, the light shone from the profile of the mountains and was nuanced. The phenomenon lasted until daybreak, the light was similar to that of the lights at local motorway junction, that is, the colour orange.

Streamers were reported in some testimonials immediately after the 6 April main shock in Pettino, Madonna della Strada and Paganica. A few cases described a dark reddish or yellow light high in the sky like an aurora.

Yellow- and rose-coloured luminous vapors were observed immediately before and after the main shock by 8 witnesses from: San Demetrio, Poggio Picenze, Barisciano, San Giacomo, Cansatessa and San Sisto. Mr Giuseppe reported seeing it from Cansatessa at about 23:30 LT on 5 April right after the first strong foreshock, $M=4.2$, the sky was blanketed with small disjointed clouds having a light violet shade. The light was brighter above the mountains. At the same time, there was a light-coloured violet fog which reached the crest of the mountains. The fog appeared stratified and very limited in luminosity along the flanks between the Mt. Ocre and Mt. Orsello or more to the north. The vapor was generally reported to be low-lying, just a few meters above the ground or covering half of the profile of the mountains along the Aterno Valley.

Luminous clouds with orange, red, pink and purple stained outlines were observed. Alberto Nuvolone from Colle Santa Maria, near Tornimparte, affirmed that the clouds were reddish at around 23:00LT, just after the 22:48 $M=4.2$ fore- shock, and he recalled that all of the sky was red and black orange until about midnight on 5 April. He also stated that red-coloured clouds covered the entire sky. The clouds were also lit far from the position of the Moon. This description was compatible with the photos taken in Poggio Picenze, see Fig. 1. The same manifestation was reported from the historical center of Aquila, Tornimparte, Roio Poggio, Roio Piano, Colle Roio, Santa Ruffina, Pile, Pettino, Cansatessa and San Giuliano. Many witnesses also observed particularly reddish clouds during the afternoon and at sunset on 6 April 6 just before a strong aftershock at 18:38, $\mathrm{M}=4.4$.

Both small and large flashes were observed lasting from a fraction of a second to a few seconds. There were 71 reports of such phenomena. Flashes were principally white, but also red and in a few cases shades of blue or indeterminate colours. Domenico Mele, who was loading a truck near Bazzano when the main shock struck, suddenly felt a hot wind, and looking towards the mountain of Bazzano saw a red semicircle of light that covered the mountain. It appeared between him and the mountain. The profile of the mountain, which is usually visible when the Moon is out, had completely disappeared behind the redness. The light was a bright flaming red. D. M. also said he saw a sign above a store illuminated by a red light. Immediately after, he heard a roar and felt the shock; a hot wind and the red glow plus thunder-like sound were present almost simultaneously. It is interesting to specify that this village is situated along the Mt. Bazzano normal fault (EMERGO, 2010) as are most of the other enumerated villages. Many eyewitnesses reported seeing flashes coming from below when observed from windows, particularly before the main shock. Before and after the main shock the flashes were not associated with thunderlike or other noises. During the main shock, the flashes were high overhead and in some cases witnesses reported that the flashes illuminated the whole sky as well as the surrounding landscape. Partially transparent clouds or no clouds were observed at the same time as the flashes. Flashes were reported 
to have appeared in Arischia, Madonna della Strada, Colle Santa Maria, Sassa, Scoppito, Coppito, the historical center of Aquila, San Sisto, Pile, Pettino, Cansatessa, Collebringioni, Aragno, Gignano, Tempera, Paganica, Camarda, Colle Roio, Santa Ruffina, Roio Poggio, Pianola, Bagno, Vallesindola of Bagno, Fossa, San Demetrio, Monticchio and Poggio Picenze.

Fourteen cases of electrical discharges were reported around and at the time of the main shock. They were observed without thunderstorms, with thin clouds through which it was possible to see the light of the stars or without clouds. Such discharges were less luminous than lightning bolts, as they did no illuminate the landscape in the neighborhoods, and they were either white, green or a shade ranging from red to violet. Fiorella De Meo, from the West Aquila highway, remembers that at the tail end of the main shock and also after it, she saw about ten thin greenish blue electrical discharges to north just above Arischia and Cansatessa. Each event was very brief, while together they lasted for about $10 \mathrm{~s}$. Some of the electrical discharges appeared simultaneously crossing each other. De Meo saw no clouds, heard no noise and reported that the landscape was not lit. Electrical discharges were also seen in Pettino, Pile, Roio Poggio, Colle Roio, Paganica and above the historical center of Aquila. After the main shock Luigi Piccirilli saw several arches of the electric discharge from the historical center of Aquila up to the Roio hill which did not illuminate anything and lasted for about $10 \mathrm{~min}$.

Thin strips of light of very short duration were observed on a few occasions. Emanuela Di Iorio, from the Acquasanta camp in Aquila, on the occasion of the aftershock on 26 April at 19:56 LT, $M=3.5$, saw a light similar to a thin laser beam. It was a white and clear blue light and appeared near Monte San Franco. It was bright and high in the sky. The beam did not illuminate any objects and was diffused on its top. It lasted about $3 \mathrm{~s}$.

Fire columns were observed during or around the time of the main shock in Bagno, Bazzano and Pile. Their colours ranged from orange to red, and in one case, the vertical column was associated with electrical discharges. Giuseppina Giuliani, from Vallesindola of Bagno, during the main shock, saw several high flames coming out of the ground near Bazzano. They were orange and came higher than Gran Sasso and completely blocked its view. A similar light was seen crossing the Aterno valley, from an opposite side, at the time of the November 1461 earthquake (Galli, 1910).

Fire beams were sighted from the historical center of Aquila, Scoppito, Sassa and Coppito. They appeared on and around the time of the stronger events. In all, 4 beams were observed, and each had a horizontal orientation. The light was either white, yellow, orange or red, and in some observations were like a beam of an automobile headlight. Marcella Del Vecchio from Pile spotted a horizontal beam of bright orange light, which was moving from North-West to SouthEast coming from Coppito toward her house during the main shock. The sky was clear and she could see the stars, the beam did not illuminate objects despite being very bright. The beam was shaped like a sickle. She had the impression that it was wrapping her house.

Luminous funnels, as conical structures of light, usually yellow, orange or red, with very well defined borders were observed. They were oriented horizontally or obliquely. They were sighted in Coppito, Sassa and Poggio Picenze before and after the main shock. Cosimo D'Ambrosio observed these funnels in Coppito after 04:00 LT on 6 April at about the time of the first strong aftershock at 04:37, $M=5.1$, looking toward Roio. He saw four distinct bundles of light beams. Each bundle was a motionless cone-shape with its point down; the point was not visible because it was hidden behind the roofs of houses. These cones were all the same colour, that is, a mix of mostly yellow plus a little light red. Regarding luminosity, the first cone was brighter than the second, the second brighter than the third and finally, the third brighter than the fourth. Furthermore, each cone appeared separately and lasted from 3 to $4 \mathrm{~s}$. Finally, each of the four bundles appeared further away in sequence. No electrical discharges were seen, and no thunder or noise were perceived. Before the appearance of the second cone there was a small shock. The intervals between bundles was about $1 \mathrm{~min}$. Therefore, the total time of the sighting was about 4 min.

Sparks of lights were viewed on several occasions before and after the main shock in the locality of Roio. They were similar to fireworks, with different colours and were not associated with booms or noises. One witness from Roio Poggio, looking over Santa Ruffina in the sky on 5 April in the evening, just near 22:48 LT, $M=4.2$ foreshock, affirmed seeing many sparks together, like when a pullover is removed. These sparks were point-like light flashes of various sizes. Together with these sparks there were electrical discharges but the latter were suspended in the sky without touching the Earth. No noises or illuminations were noted.

Fire balls were observed several months before the main shock on 6 April. As with foreshock activity which started to increase in October 2008 (Pondrelli, 2010), reports of fire balls started in the summer of 2008 and increased in number till the end of March 2009. Marcelli Gabriella from Poggio Picence observed a ball of light toward Monte Ocre, about 06:15-06:30 LT at the beginning of March 2009. That morning, it was still dark and a light was seen along the flank of the mountain. It was bigger than a street light, the luminous sphere was yellowish orange. This light remained midway up the mountain and then it suddenly moved up to the mountain top and then disappeared behind it. The mountain profile was visible because it was completely covered in snow. Another 25 bright spherical bodies were sighted above the historical center of Aquila, around Roio hill, near Preturo and Pettino, Collebringioni, Tempera, Bagno, above San Demetrio, Corvo Mountain, near Passo delle Capannelle, inside the Celano gorges, near Popoli and Alba Fuciens. Their white, yellow, orange or red lights were not bright. Then 


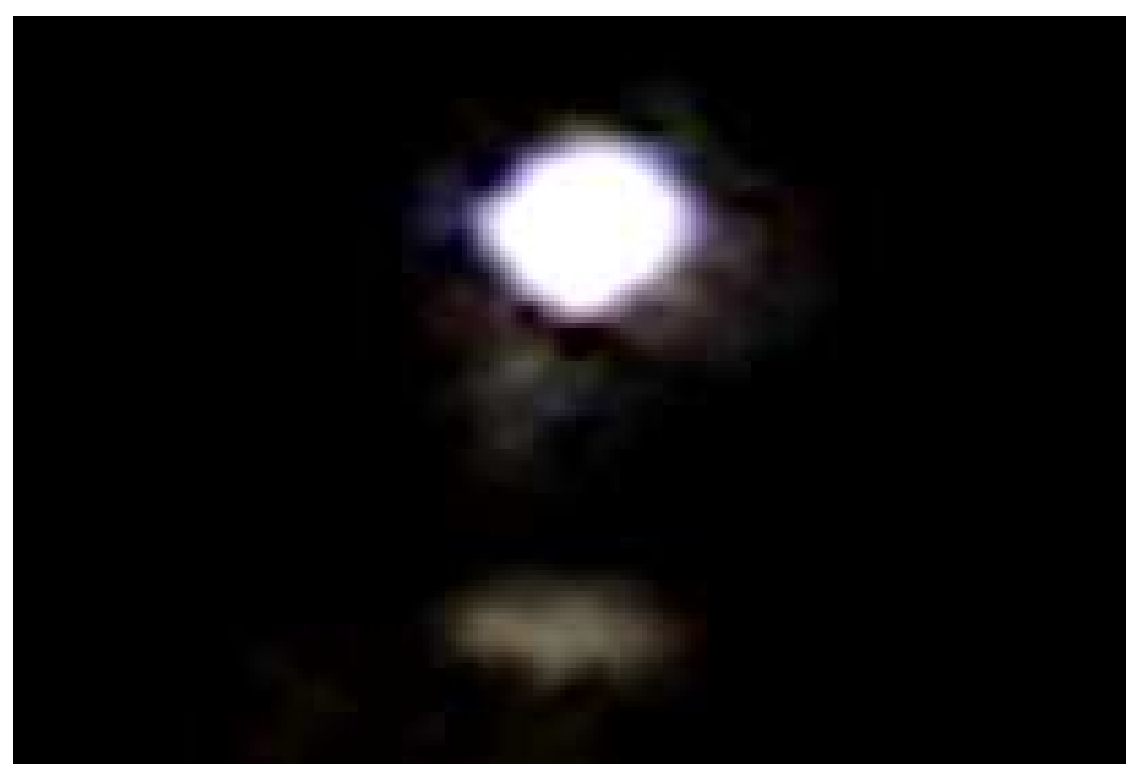

Fig. 2. A luminous sphere observed at 01:53 LT on 22 February 2009, near Preturo. Courtesy of Giuseppe Marrone.

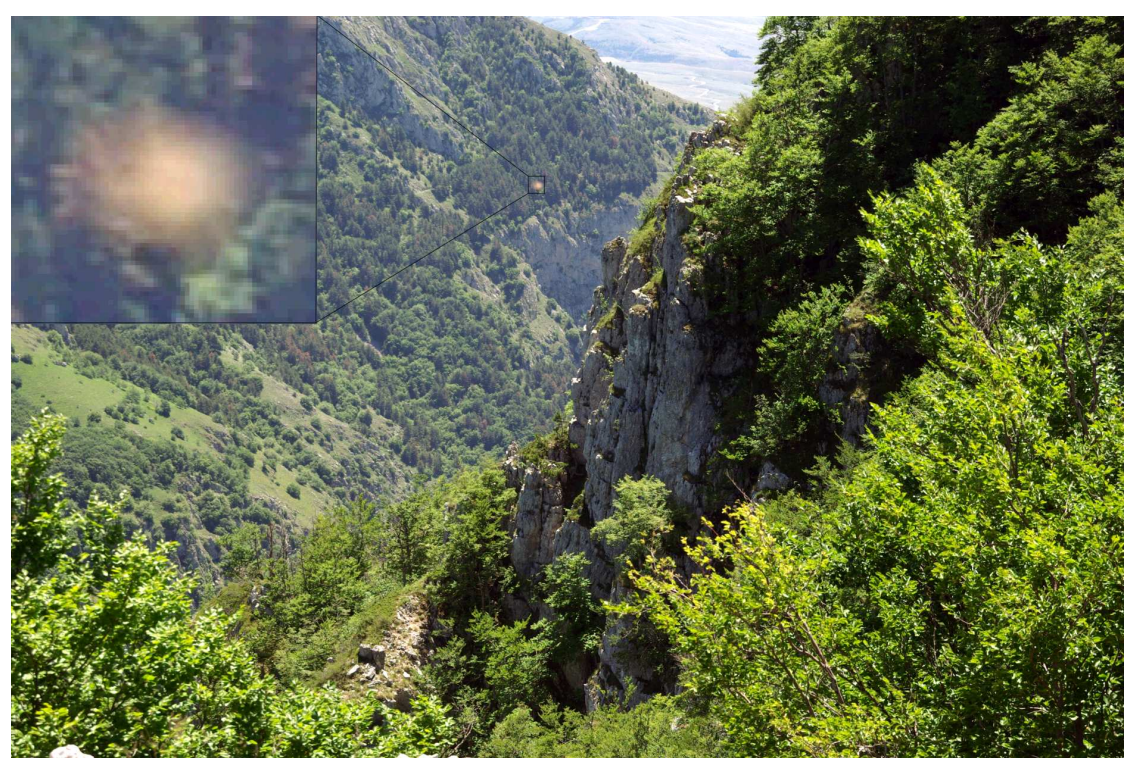

Fig. 3. A luminous body from the Celano Gorges, about $30 \mathrm{~km}$ south of Aquila, at about 11:14 LT on 20 June 2008. Courtesy of Bruno Chiarelli.

diameters ranged from a few centimeters to one meter. In four cases, they appeared in groups of two to four spheres. In at least eight cases, globular lights were seen moving at low velocity and in one case at high velocity. Several photos and videos were collected which documented the phenomena, see Figs. 2 and 3. Figure 2 is a photogram of a video recorded on a MOTOROLA RAZR V3i mobile. It was captured from Madonna della Strada towards Preturo Airport (East), initially the luminous ball fell from the sky with fast movements and then it remained suspended above the ground for more than $30 \mathrm{~min}$. The angle with respect to the horizon was estimated at about $20-30^{\circ}$. Figure 3 was not intended to capture the luminosity, in fact, the author of the photo had no idea that he was capturing such an object. The photo was taken in the Celano gorges which are in close proximity to the Ovindoli-Pezza normal fault (D'addezio, 1996). This photo was taken with a PENTAX K10D camera.

Flames were observed during but mostly after the main shock up till about 04:30 LT on 6 April. Nearly all of the 23 sightings were reported as big red flames of up to $10 \mathrm{~m}$. 
These appeared near the Aterno River, mostly south of Aquila, while, three flames were observed near the highway junction of Aquila. Their duration was about 5 to $20 \mathrm{~s}$ and no noises were heard with them. However, a strong smell of gas was noted in some case but not recognised. Michele Giuliani, after the main shock, at about 03:50 LT 6 April, was traveling along the Mausonia Road. He saw huge flames when he looked down from Civita di Bagno towards Paganica and Bazzano. The flames were coming from the ground in an unpredictable order and were yellow, orange and red. The sightings lasted about half an hour and every flame lasted more than a second. They were higher than $10 \mathrm{~m}$ and were inclined.

Small flames were observed exclusively during the main shock above the cement and wooden utility poles, in San Sisto, as well as in the historical center of Aquila. In the latter case small flames were seen coming out from between the cobblestones of Viale Francesco Crispi. The witness said that he saw many small flames, about $10 \mathrm{~cm}$ tall, which were a few centimeters above the street. Their light was dull and lasted several seconds. All of this took place while he was standing in Duomo Square looking toward Villa Comunale. These small flames were seen just seconds before the main shock.

Undetermined lights were all of very short duration and were sighted through window blinds, shutters or reflected on some surface. At about 01:30 LT on 6 April, just two hours before the main shock, Carlo Strinella saw two white light flashes reflected on the furniture of the kitchen, whose shutter was open. The second flash was intense as daylight, lasted more than $1 \mathrm{~s}$, and was left impressed on his retinas. He checked that everything was fine in the kitchen, and looked out the window but saw the stars, and did not hear thunder. Then, he remembered having read an EQL summary a few months earlier (Silvestri, 1999) and decided to take his family to a safer structure. The sighting was near Pettino along state highway 80 and the kitchen window looked towards Coppito (West). He also noticed that the air temperature outside had sensibly warmed up during the night in comparison with the feeling he had immediately after dinner time, at about 21:00 LT.

\section{EQL classifications and its space-time evolution}

This study began to order and classify the testimonials; this was done with reference to Galli's work (Galli, 1910).

\subsection{EQL classification and timing}

This classification, which summarises the types described above, can be found in Table 3. It is slightly different from that which had already been utilised (?), as the name Lightning was changed to Flashes, the type called Sprinkles was incorporated into Sparks and Electrical discharges which was added here. Furthermore, the witnesses far from the epicenter could have seen lights slightly before the main shock, since light travels faster than seismic waves. This was considered by including such sightings as simultaneous in Table 3. It shows that undetermined phenomena and flashes were mostly observed during the main shock. Undetermined lights, which only occurred in a few cases, were almost all seen from inside houses and are indicated with three " $U$ " in Table 1, in the Supplement (http://www.nat-hazards-earth-syst-sci.net/ 10/967/2010/nhess-10-967-2010-supplement.pdf). On the other hand, flash was the most frequently reported phenomena and all observations were made from outdoors. There were phenomena observed after the shocks, and these were mostly electrical discharges and flames. Finally, there were phenomena observed mostly before the stronger shocks: fire balls, luminous clouds and diffused lights. All other types of sightings appear in Table 3 with a small numbers of cases.

To better classify relative frequency of luminous phenomena Galli suggested grouping the forms into four types (Galli, 1910), see Table 4. Different from Galli, undefinable instantaneous illuminations, which is the union of the first four types and principally anticipated the shocks in the past catalogue, appeared with major frequency during the main shocks. Well delimited and mobile luminous masses, which included luminous globes, columns, beams and funnels, appeared mostly before the shocks, whereas in the Galli collection these appeared mostly during the shock. Unlike Galli, flames and shiny emanations, which included flames, sparks and vapors appeared mostly after, and phosphorescence of the air and clouds, which were the union of the last three in Table 3, appeared mostly before, compared to the times of stronger shocks according to Galli. In comparing these frequencies with those obtained in Galli's work we should remember that, unlike Galli, they concerned only one earthquake.

\subsection{Spatial distribution and correlation with geological structures}

One advantage in considering observations of a single event is that their characteristics can be compared to today's existing geological studies of that specific area (Bagnaia, 1992), source parameters (Galli, 1910) and dynamics (Galli, 1910) of the earthquake. Hence, a spatial distribution of the sightings associated with the Aquila earthquake was taken into account; this is depicted in Fig. 4. From such a distribution, there appears to be a prevalence of some kind of phenomena in different geographical zones. For example, electrical discharges were observed mostly above Aquila and to the north-west, while flames were observed principally along the Aterno Valley, south-east of Aquila. It was not possible to think that the electrical discharges reported by witnesses were all short circuits of high voltage lines, as they had an enormous length and their distance from the ground was great, even if high voltage lines were present in the 
Table 3. The Aquila collection was ordered in accordance with the Galli classification.

\begin{tabular}{lcccccc}
\hline $\begin{array}{l}\text { Types } \\
\text { (shape and size })\end{array}$ & $\begin{array}{c}\text { Before } \\
(\#)\end{array}$ & $\begin{array}{c}\text { During } \\
(\#)\end{array}$ & $\begin{array}{c}\text { After } \\
(\#)\end{array}$ & $\begin{array}{c}\text { Sum } \\
(\#)\end{array}$ & $\begin{array}{c}\text { Uncertain } \\
(\#)\end{array}$ & $\begin{array}{c}\text { Total } \\
(\#)\end{array}$ \\
\hline Undetermined & 1 & 6 & 1 & 8 & - & 8 \\
Flashes & 18 & 25 & 22 & 65 & 6 & 71 \\
Electrical discharges & 1 & 5 & 8 & 14 & - & 14 \\
Thin strips of light & 1 & 1 & 1 & 3 & - & 3 \\
Fire balls & 18 & - & 6 & 24 & 2 & 26 \\
Fire columns & 1 & 1 & - & 2 & - & 2 \\
Fire beams & 1 & 1 & 1 & 3 & 1 & 4 \\
Luminous funnels & 5 & - & 2 & 7 & - & 7 \\
Flames & 4 & 6 & 12 & 22 & 1 & 23 \\
Small flames & - & 2 & - & 2 & - & 2 \\
Sparks & 1 & 1 & 2 & 4 & - & 4 \\
Luminous vapors & 4 & - & 4 & 8 & - & 8 \\
Luminous clouds & 20 & 2 & 4 & 26 & 2 & 28 \\
Diffused lights & 24 & 4 & 9 & 37 & 1 & 38 \\
Streamers & - & - & 3 & 3 & - & 3 \\
\hline All & 99 & 54 & 75 & 228 & 13 & 241 \\
\hline
\end{tabular}

Table 4. The four groups in which the forms can be assembled, according to Galli.

\begin{tabular}{lcrrrr}
\hline Groups & $\begin{array}{l}\text { Before } \\
(\#)\end{array}$ & $\begin{array}{l}\text { During } \\
(\#)\end{array}$ & $\begin{array}{l}\text { After } \\
(\#)\end{array}$ & $\begin{array}{l}\text { Uncertain } \\
(\#)\end{array}$ & $\begin{array}{l}\text { Total } \\
(\#)\end{array}$ \\
\hline Undefinable instantaneous illuminations & 21 & 37 & 32 & 6 & 96 \\
Well delimited and mobile luminous mass & 25 & 2 & 9 & 3 & 39 \\
Flames and shiny emanations & 9 & 9 & 18 & 1 & 37 \\
Phosphorescence of the air and clouds & 44 & 6 & 16 & 3 & 69 \\
\hline
\end{tabular}

territory. On the other hand, positions of the flames were very well correlated with the Aterno River and the main gas pipeline, but in agreement with other works (Hieke, 2004) it would have been difficult to ignite gas without a primer. Furthermore, flames were always red and did not cause fires nor were there any burn traces. The question can be raised if they were real flames or flame-like lights, as, no natural reservoir within the geological formation of this Valley was known while the presence of a primer was unlikely.

Electrical discharges were of two types: vertical and horizontal. Vertical discharges always originated from the ground, reached up to one kilometer, and they were localized exclusively over the graben edges or along the sides of flat areas within the Aterno Valley. Whereas, horizontal discharges were located only over the asperity and mountains, rarely originating from the ground, sometimes linking both the asperity and the mountains. This may indicate the presence of high electrical potential differences, 1) between two horsts; and 2) between graben edges and atmosphere at horst altitude. Flames were principally located to the west of the
Graben delimited by Paganica and the Bazzano faults; within a morphologically flat area of the Aterno Valley, low-lying compared to the surrounding zones. This flat area corresponds to the area of maximum negative vertical deformation derived from the SAR data (Atzori, 2009). The Aterno Valley is partly filled with Pleistocene lacustrine deposits formed by a complex sequence of pelitic and coarse grained units (Bertini, 1989), with frequent lateral variations, overlying the bedrock. This area seems to represent the morphological expression of deeper tectonic movements (Vezzani, 1998).

\subsection{Other classifications}

Following Galli's work, the classification of this collection was problematic, because many sightings were difficult to assign to the types defined above. In fact, a clear red sky was often associated with red clouds and coloured fogs. While flashes were usually without electrical discharges, and the latter were often observed as huge but not significant flashes. Light columns and light beams usually had only a colour 


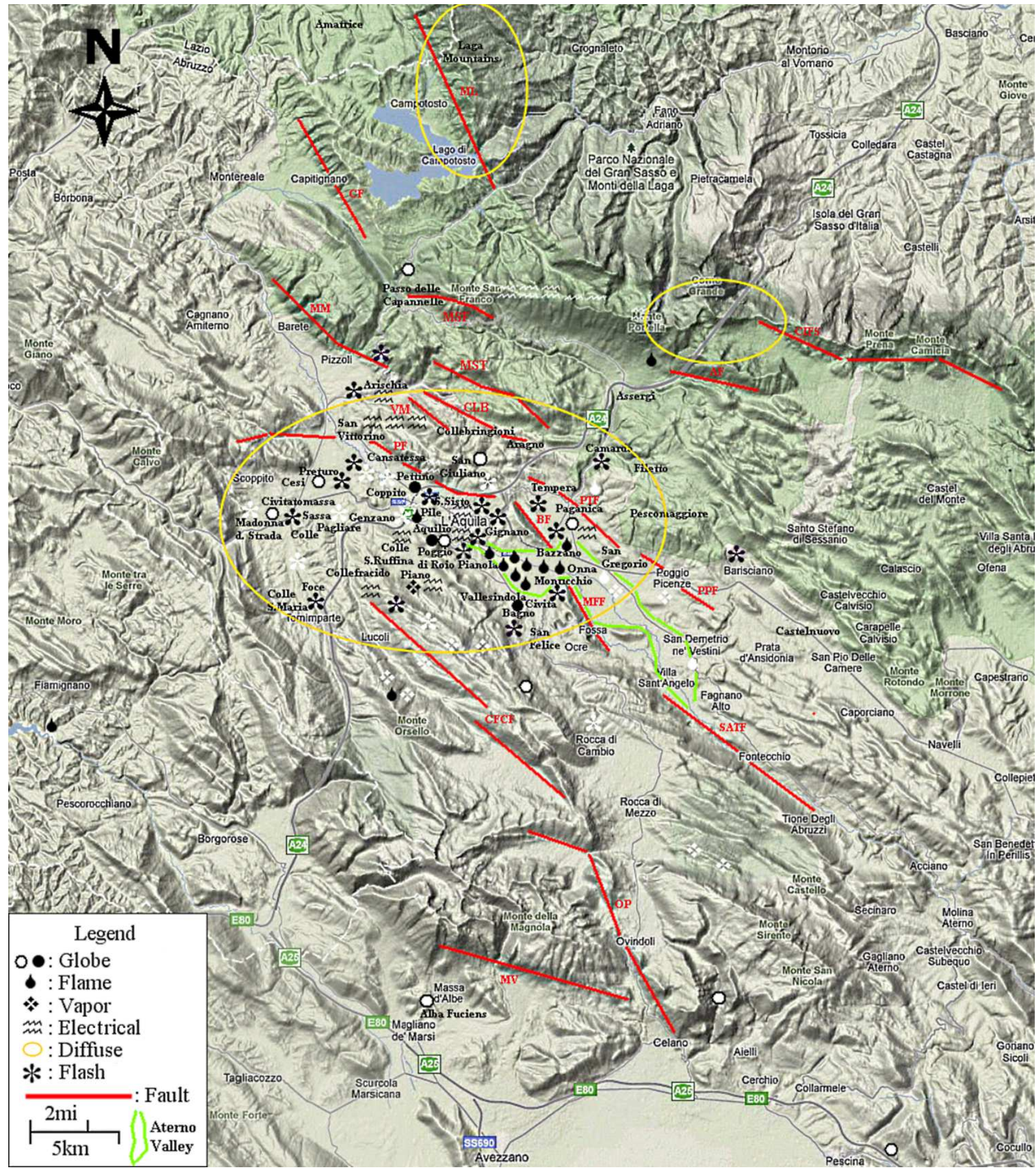

Fig. 4. Geographical distributions of EQLs on the map retrieved from Google Maps website http://maps.google.pt/; the symbols were specified in the legend; black colour indicate during and after the main shock, white colour indicate before. Primary active faults in the region of the sightings were indicated with red lines: ML, Monts of Laga Fault; CF, Capitignano Fault; MM, Mount Marino Fault; MSF, Mount San Franco Fault; MST, Mount Stabbiata Fault; CLB, Collebringioni Fault; VM, Valle del Machione Fault; AF, Assergi Fault; CIFS, Campo Imperatore Fault System; PF, Pettino Fault; PTF, Paganica-Tempera Fault; BF, Bazzano Fault; PPF, Poggio Picenze Fault; MFF, Monticchi-Fossa Fault; CFCF, Campo Felice-Colle Cerasitto Fault; SATF, Sant'Angelo-Tione Fault; Ovindoli-Pezza Fault; MV, Mont Velino Fault. Fault location from EMERGO (2010). 
Table 5. The Montandon classification of the Aquila collection.

\begin{tabular}{lrrr}
\hline Types & $\begin{array}{l}\text { Before } \\
(\#)\end{array}$ & $\begin{array}{l}\text { During } \\
(\#)\end{array}$ & $\begin{array}{l}\text { After } \\
(\#)\end{array}$ \\
\hline "Lighting" & 20 & 33 & 25 \\
"Luminous bands" & 7 & 3 & 3 \\
"Globular lights" & 15 & - & 6 \\
"Fire tongues" & - & 2 & - \\
"Flames" & 4 & 6 & 12 \\
\hline
\end{tabular}

similar to fire, while in several cases flames were so huge that some questions were raised about their nature. Sparks could be observed in all of the other types and there were few luminous funnels each very different from the other.

New, simpler and less precise classifications were proposed after Galli's work, discarding events observed during stormy or unsettled weather, which used the words "similar to", "like" and "sometimes called" (Montandon, 1948). This was because the physical phenomena of such luminosity were truly unknown and their association was based on similarity. Therefore, it was suggested that the use of names belonging to similar, known phenomena should be done with caution (St-Laurent, 2000). The simpler Mountadon classification was applied to the Aquila collection after discarding testimonials which happened when weather, time or location of sightings was undetermined. Furthermore, early sightings in the summer of 2008 and late September 2009, plus luminous vapors, luminous clouds, diffused lights and streamers were discarded; after which 136 cases remained (Table 5). Not very different from the Galli classification, "flashes" appeared prevalently during the main shock, "luminous" bands and "flames" appeared after this, while "globular lights" appeared before.

With such an abundant set of data, we were able to put the testimonials into a different order or split the sightings into different types. As already suggested by Galli, an alternative way to order the collection could be to base it on their distance from the ground. Being so, we divided the sighting positions into: ground based, above the horizon and high in the sky, as seen in Table 6. Luminosity which appeared to touch the ground were observed mostly before and after the main shock as well as the above the horizon lights, while lights high in the sky were mostly observed during the quake. The shape of the light was also taken in account, but only spherical shapes were sighted before the quake. Horizontally and vertically stretched lights were mainly observed after the quake, and the percentage of vertical ones was greater. Undetermined shapes were observed during and around the quake time. Finally, the light movement was also subdivided: horizontal, vertical or still. Both movements were observed mostly before the quake, while stationary objects were principally observed after the main shocks.
Table 6. Altitude, shape and movement direction classifications of the Aquila collection.

\begin{tabular}{lrrr}
\hline Types & $\begin{array}{l}\text { Before } \\
(\#)\end{array}$ & $\begin{array}{l}\text { During } \\
(\#)\end{array}$ & $\begin{array}{l}\text { After } \\
(\#)\end{array}$ \\
\hline Ground based & 19 & 13 & 21 \\
Above the horizon & 23 & 20 & 25 \\
High in the sky & 5 & 8 & 5 \\
Horizontal stretched & 4 & 4 & 9 \\
Vertical stretched & 11 & 11 & 13 \\
Globular & 15 & - & 5 \\
Undetermined & 17 & 26 & 24 \\
Horizontal movement & 6 & 1 & 3 \\
Vertical movement & 6 & 2 & 2 \\
Still & 35 & 38 & 46 \\
\hline
\end{tabular}

In contrast to the diffused light, whose duration was much longer than the other sightings, all forms of light were limited in size. Even the largest flashes were rarely seen at a distance of more than ten kilometers and their horizontal extension did not appear to exceed a few kilometers. Regarding their altitude, we have data from a station in Rieti, ITATOR Project (http://itator.itacomm.net/), which looked towards the area of the earthquake and which was dedicated to capturing video sprites. Such recordings assure us that the luminosity did not reach an altitude of $4.3 \mathrm{~km}$ above the city of Aquila (Valeri, 2009). So, we deduced that all the luminous activity involved a limited portion of the stratosphere above the epicenter, extending between 10 to 50 times more in horizontally than vertically.

\section{Conclusions}

A questionnaire was prepared to collect testimonials regarding luminous and other non-common phenomena from Abruzzo residents after the strong quake of 6 April 2009. About one thousand phenomena were reported of which 241 were luminous phenomena. Several photos included luminous phenomena. At least 99 of such phenomena occurred before the main shock and other strong events of the seismic sequence, whereas globular lights, luminous clouds and diffused light were more frequent before the quakes. Luminous events were observed before the main shock without the ground shaking and were very similar to those reported about two centuries ago. Given this, they could be considered premonitory phenomena. Finally, the experience of Carlo Strinella, who had knowledge of EQL, took measures to protect his family after interpreting some flashes he had sighted before the main shock. This suggests that educating the general population about EQL phenomena could help save lives. 
Several classifications were experimented for ordering the collection. Difficulty in deciding which types corresponded to the testimonials led to the adoption of more recent and less precise classifications. Given the large number of testimonials, a spatial ordering was also proposed. From this, two particular forms of lights were selected, electric discharges and flames, which were compared to geological settings and geophysical dynamics. Electric discharges, mostly observed north-west of Aquila, were sighted on the geological borders of the Aterno Valley corresponding to the quake movement (Walters, 2009), principally after the main shock. Flames, observed south-east of Aquila in the area of maximum negative vertical deformation, also occurred after the main shock.

Today, digital video facilities can record such phenomena and software solutions are also available for capturing fast, low luminous phenomena such as meteors and sprites, see for example (Silvestri, 2008); while spectra can give information about their distance and nature (Stephan, 2009). The development of a video network along the Apennin chain, principally in the flat basins where the population lives and strong earthquakes occur, would not be very expensive. Such a system could be used to detect premonitory phenomena in the case of a long foreshock period, as in the Aquila seismic sequence. The creation of a permanent video sensing network is not the only possible solution. Since major earthquakes in Italy have generally been preceded by weak seismic activity, which have not always culminated in strong shocks, a temporary video sensing network would be useful.

Acknowledgements. The author would like to gratefully thank the hundreds of "Abruzzesi" for contributing their valuable testimonials with particular thanks to Massimo Orsini, Cettina Di Cola, Carlo Strinella, Marta Torelli, Antonio Rosettini, Laura Frattura, Federico Andreassi, Marilena De Salvatore, Mario De Martino and Suor Teresa. I am particularly grateful to France St-Laurent for her constructive comments, remarks and corrections. Thanks to Lucia Miconi, Giuseppe Marrone, and Bruno Chiarelli for their photos. Thanks go to Piergiovanni Di Zitti and Stefano Rosone of the meteorological network AQ Caput Frigoris (http://www.caputfrigoris.it/) for weather data. The author would also like to thank Massimo Silvestri, Renzo Cabassi, Nico Conti, Roberto Labanti and Giuseppe Stilo of CIPH SOSO for their precious observations and materials. In addition, the author would like to thank Diego Valeri for his valuable input regarding sighting verifications. Finally, thanks to "la Protezione Civile Italiana", "la Polizia Municipale dell'Aquila", "i Vigili del Fuoco dell'Aquila" and "la Guardia Forestale".

Edited by: M. E. Contadakis

Reviewed by: F. St-Laurent and another anonymous referee

\section{References}

Alfano, G. B.: Il terremoto irpino del 23 luglio 1930, Pubblicazioni dell'Osservatorio di Pompei, Scuola Tipografica Pontificia per i Figli dei Carcerati, Pompei, 57 pp., 1931 (in Italian).

Araiza-Quijano, M. R. and Hernandez del Valle, G.: Some observations of atmospheric luminosity as a possible earthquake precursor, Geofis. Int., 35, 403-408, 1996.

Atzori, S., Hunstad, I., Chini, M., Salvi, S., Tolomei, C., Bignami, C., Stramondo, S., Trasatti, E., Antonioli, A., and Boschi, E.: Finite fault inversion of DInSAR coseismic displacement of the 2009 L'Aquila earthquake (central Italy), Geophys. Res. Lett., 36, L15305, doi:10.1029/2009GL039293, 2009.

Bagnaia, R., D'Epifanio, A., and Labini, S. S.: Aquila and subequan basin: an example of quaternary evolution in Central Appennines, Italy, Quaternaria Nova, II, 187-209, 1992.

Bertini, T., Bosi, C., and Galadini, F.: La conca di Fossa-S. Demetrio dei Vestini, in: CNR, Centro di Studio per la Geologia Tecnica, ENEA, P.A.S. in Elementi di tettonica pliocenicoquaternaria ed indizi di sismicita olocenica nell'Appennino laziale-abruzzese, Societa Geologica Italiana, L'Aquila, 26-58, 1989 (in Italian).

Bindi, D., Pacor, F., Luzi, L., Massa, M., and Ameri, G.: The $M_{\mathrm{W}}=6.3,2009$ L'Aquila earthquake: source, path and site effects from spectral analysis of strong motion data, Geophys. J. Int., 179, 1573-1579, 2009.

Bird, D. K.: The use of questionnaires for acquiring information on public perception of natural hazards and risk mitigation - a review of current knowledge and practice, Nat. Hazards Earth Syst. Sci., 9, 1307-1325, 2009,

http://www.nat-hazards-earth-syst-sci.net/9/1307/2009/.

Brady, B. T. and Rowell, G. A.: Laboratory investigation of the electrodynamics of rock fracture, Nature, 321, 488-492, 1986.

Chiarabba, C., Amato, A., Anselmi, M., et al.: The 2009 L'Aquila (central Italy) MW=6.3 earthquake: Main shock and aftershocks, Geophys. Res. Lett., 36, L18308, doi:10.1029/2009GL039627, 2009.

D’Addezio, G., Pantosti, D., and Marco de Martini, P.: Paleoseismologic and geomorphic investigations along the middle portion of the Ovindoli-Pezza Fault (Central Italy), Ann. Geofis., XXXIX(3), 663-675, 1996.

Derr, J. S.: Earthquake lights: a review of observations and present theories, B. Seismol. Soc. Am., 63, 2177-2187, 1973.

EMERGO Working Group: Evidence for surface rupture associated with the Mw 6.3 L'Aquila earthquake sequence of April 2009 (central Italy), Terra Nova, 22, 43-51, 2010.

Enomoto, Y. and Zheng, Z.: Possible evidences of earthquake lightning accompanying the 1995 Kobe earthquake inferred from the Nojima fault gouge, Geophys. Res. Lett., 25, 2721-2724, 1998.

Fidani, C.: Alcune considerazioni sui fenomeni luminosi del terremoto dell' Aquila, Comitato Italiano Progetto Hessdalen (CIPH), available at: http://www.itacomm.net/EQL/2009_FIDANI.pdf, 2009a.

Fidani, C.: Fenomeni luminosi hanno accompagnato il terremoto del 6 aprile 2009, Bollettino Geofisico, to be published, 2010.

Fidani, C.: Ipotesi sulle anomalie elettromagnetiche associate ai terremoti, Libreria Universitaria Benedetti Ed., Aquila, 300 pp., 2005 (in Italian). 
Fidani, C.: Luminous and other non seismic phenomena associated to the April 6, 2009, Aquila earthquake, Gruppo Nazionale Geofisica della Terra Solida (GNGTS) Trieste, 2009b.

Finkelstein, D., Hill, U. S., and Powell, J. R.: The piezoelectric theory of earthquake lightning, J. Geophys. Res., 78, 992-993, 1973.

Freund, F.: Charge generation and propagation in rocks, J. Geodyn., 33, 545-572, 2002.

Freund, F. T., Kulahci, I. G., Cyr, G., Ling, J., Winnick, M., Tregloan-Reed, J., and Freund, M. M.: Air ionization at rock surfaces and pre-earthquake signals, J. Atmos. Sol.-Terr. Phy., 71, 1824-1834, 2009.

Galli, I.: Raccolta e classificazione di fenomeni luminosi osservati nei terremoti, Boll. Soc. Sismol. Ital., XIV, 221-448, 1910 (in Italian).

Hieke, W.: The August 27, 1886 earthquake in Messenia (Peloponnesus) and reported flames over the Ionian Sea a Mediterranean Ridge gas escape event?, Mar. Geol., 207, 259-265, 2004.

Johnston, C.: Light from seismic waves, Nature, 354, 361 pp., 1991.

Lira, A.: Time difference correlation between seimic waves and earthquake lights, Seismol. Res. Lett., 79, 516-519, 2008.

Lockner, D. A., Johnston, M. J. S., and Byerlee, J. D.: A mechanism to explain the generation of earthquake lights, Nature, 302, 2833, 1983.

Lockner, D. A. and Byerlee, J. D.: Complex resistivity of fault gouge and its significance for earthquake lights and induced polarization, Geophys. Res. Lett., 12, 4, 211-214, 1985.

Matteucig, G.: Terremoti: Ecologia - Etnologia, Raccolta di Relazioni, Comunicazioni ed Interventi sul Comportamento degli Animali in Relazione alle Variazioni Geochimicofisiche Ambientali Precedenti Sismi (Zoologia e Fisica dei Precursori per una Nuova Cultura della Protezione Civile), Ed. AMPA in Melito (NA), 128 pp., 1985.

Montandon, F.: Lueurs and malaises d'origine seismique, Geographica Helvetica, 3(1), 157-178, 1948.

Oddone, E.: Studio sul terremoto avvenuto il 23 luglio 1930 nell'Irpinia, Perugia, Meteor. Prat., 13, 77-84 and 116-125, 1930 (in Italian).

Persinger, M. A. and Derr, J. S.: Geophysical Variables and Behavior: LXII, Temporal coupling of ufo reports and seismic energy release within the Rio Grande rift system: discriminative validity of the tectonic strain theory, Perceptual ans Motor Skills, 71, 567-572, 1990.

Piccardi, L.: Paleoseismic evidence of legendary earthquakes: The apparition of Archangel Michael at Monte SantAngelo (Italy), Tectonophysics, 408, 113-128, 2005.

Pondrelli, S., Salimbeni, S., Morelli, A., Ekstrom, G., Olivier, M., and Boschi, E.: Seismic moment tensors of the April 2009, L'Aquila (Central Italy), earthquake sequence, Geophys. J. Int., 180(1), 238-242, 2010.

Protezione Civile: Abruzzo e Noi, A cura della Presidenza del Consiglio dei Ministri, Dip. Protezione Civile, No. 15, 6 settembre 2009 (in Italian).
Sarantakos, S.: Social Research, 2nd edn., Palgrave Macmillan Hampshire, 464 pp., 2005.

Schloessin, H.: Experiments on the electrification and luminescence of minerals and possible origins of EQLs and sferics, Ann. Geophys., 3, 709-720, 1985, http://www.ann-geophys.net/3/709/1985/.

Sieberg, A. and Lais, R.: Das mitteleuropaische Erdbeben von 16 Nov. 1911, Veroff. Reichsanst. f. Erdb. fors. i. Jena, Heft 4, 1911 (in German).

Silvestri, M.: Introduzione alle Luci Sismiche, Bologna, 19992001, available at: http://www.itacomm.net/EQL/eqlidx_i.htm and: EQL EarthQuake Light, Introduzione, available at: http://www.itacomm.net/PH/CIPH/EQL.html, 1999 (in Italian).

Silvestri, M.: Come Realizzare SOSO: Smart Optical Sensors Observatory, available at: http://www.ciph-soso.net/SOSO/SOSO\% 3A_REALIZZAZIONE.html(last access: April 2010), 2008.

Soter, S.: Macroscopic seismic anomalies and submarine pockmarks in the CorinthPatras rift, Greece, Tectonophysics, 308, 275-290, 1999.

Stephan, K. D., Ghimire, S., Stapleton, W. A., and Bunnell, J.: Spectroscopy applied to observations of terrestrial light sources of uncertain origin, Am. J. Phys., 77(8), 697-703, 2009.

St-Laurent, F.: The Saguenay, Québec, earthquake lights of November 1988-January 1989, Seismol. Res. Lett., 71, 160-174, 2000.

St-Laurent, F., Derr, J., and Freund, F.: Earthquake lights and the stress-activation of positive hole charge carriers in rocks, Phys. Chem. Earth, 31, 305-312, 2006.

Stothers, R. B.: Ancient and modern earthquake lights in northwestern Turkey, Seismol. Res. Lett., 75, 199-204, 2004.

Terada, T.: On luminous phenomena accompanying earthquakes, Bull. Earthq. Res. Inst. Univ. Tokyo, 9, 225-255, 1931.

Terada, T.: Luminous phenomena accompanying destructive sea waves (Tsunamis), Bull. Earthq. Res. Inst. Univ. Tokyo, 3, 25 35, 1934.

Valeri, D.: Rieti instrumentation was on during the same period of the Aquila earthquake, no luminous phenomena were detected, Diego Valeri calculated minimum detected altitude above the Aquila city, personal communication, 2009.

Vezzani, L. and Ghisetti, F.: Carta Geologica dellAbruzzo, scale 1:100 000, S.EL.CA., Firenze, 1998 (in Italian).

Walters, R. J., Elliott, J. R., D’Agostino, N., England, P. C., Hunstad, I., Jackson, J. A., Parsons, B., Phillips, R. J., and Roberts, G.: The 2009 L'Aquila earthquake (central Italy): A source mechanism and implications for seismic hazard, Geophys. Res. Lett., 36, L17312, doi:10.1029/2009GL039337, 2009.

Yasui, Y.: A summary of studies on luminous phenomena accompanied with earthquakes, Memoirs Kakioka Magnetic Observatory, 15, 127-138, 1973. 